\title{
Sistem Pemantauan Tegangan Listrik Menggunakan Mikrokontroler AT Mega 328 Berbasis Web
}

\author{
Rudi Kurniawan' ${ }^{1}$, Harma Oktafia Lingga Wijaya ${ }^{2}$, Aditya Nugroho ${ }^{3}$ \\ STMIK Musirawas \\ Jl. Jend. Besar H.M Soeharto Kel, Lubuk kupang Kec Lubuklinggau Utara II Kota Lubuklinggau \\ Email : khurniawa.ruenta@gmail.com, harmaoktafialingga@gmail.com
}

\begin{abstract}
Electricity is the source of the needs of people all over the world with electricity all human work will be easy, the main thing is electricity is a source of lighting without electricity, so there will not be an era and technology, but the use of electricity by many people who do not care about the electricity impact is a lot short circuit and fire because many electricity users do not know the current of electric current in their homes. Thus the author makes a tool that can measure the voltage used. Tools made using ACS712 and Arduino Uno sensors and Ethernet shield. The sensor will read the power supply voltage and then process it to Arduino Uno and Ethernet shield. After processing via Arduino, the ACS712 sensor readings will be displayed on the web page.
\end{abstract}

Keywords: Electricity, ACS712 Sensor, Arduino uno, Ethernet Shield, Web

\begin{abstract}
Abstrak
Listrik adalah sumber kebutuhan masyarakat seluruh dunia dengan adanya listrik semua pekerjaan manusia akan menjadi mudah yang paling utama listrik adalah sumber penerangan tanpa adanya listrik maka tidak akan maju suatu zaman dan teknologi, namun penggunaan listrik oleh masyarakat banyak yang tidak peduli akan dampak listrik sehinggan banyak terjadi konsleting dan kebakaran karena pengguna listrik banyak tidak mengetahui teganan arus listrik yang ada dirumah-rumahnya. Dengan demikian penelitian membuat sebuah alat yang dapat mengukur tegangan listrik yang digunakan. Alat yang dibuat menggunakan sensor ACS712 dan arduino uno serta ethernet shield. Sensor akan membaca sautu tegangan listrik lalu diproses ke arduino uno dan ethernet shield. Setelah diproses melalui arduino maka hasil pembacaan sensor ACS712 akan ditampilkan di halaman web.
\end{abstract}

Kata kunci: Listrik, Sensor ACS712, Arduino uno, Ethernet Shiled, Web

\section{PENDAHULUAN}

Dimasa sekarang perkembangan dan kemajuan dari ilmu pengetahuan dan teknologi telah membawa banyak perubahan terhadap peradaban manusia, salah satunya perkembangan teknologi di dunia elektronika. Dengan perkembangan teknologi di dunia elektronik, tidak dipungkiri memberikan kemajuan bagi suatu negara. Misalnya pemantauan perangkat elektronik terhadap daya listrik pada tegangan dan arus mengalami perkembangan pesat. Dengan mikrokontroler pemantauan listrik dapat dipantau dengan otomatis melalui web. Penelitian ini dilakukan di POLRES (Kepolisian Resor) 
kota lubuklinggau. Pemantauan listrik di lokasi penelitian tersebut masih terbilang jarang bahkan tidak pernah dipantau secara teratur, pengecekannya masih menggunakan cara manual yang merepotkan. Peran listrik menjadi unsur penting dalam berbagai hal di dalam masyarakat masa kini. listrik menimbulkan berbagai macam efek yang telah umum diketahui, seperti petir, listrik statis, induksi elektromagnetik dan arus listrik. Semua alat elektronik yang dipakai dikehidupan masyarakat menggunakan listrik, misalkan TV, Komputer, AC dan lain-lain. Ketidaktahuan akan besar kecilnya tegangan menjadi sebuah masalah tersendiri, peningkatan penggunaan energi listrik tentunya menghabiskan sumber energi tak terbaharukan yang ada sekarang jika pemanfaatannya tidak efektif dan efisien. Berdasarkan permasalahan yang dipaparkan diatas, peneliti ingin memberikan solusi untuk memantau tegangan listrik secara otomatis, simple, aman, menarik, dan terperinci dengan menggunakan aplikasi web site dengan Mikrokontroler AT Mega 328. bentuk perangkat elektronika Mikrokontroler AT Mega 328 tersebut bertujuan untuk memantau tegangan dan arus listrik dengan menggunakan modul ACS721 dan Ethernet Shield

\section{METODOLOGI PENELITIAN}

\subsection{Ethernet Shield}

Merupakan modul yang digunakan untuk mengkoneksikan Arduino dengan internet menggunakan kabel (Wired) dengan cara memberikan layanan IP pada arduino dan pc agar dapat terhubung ke internet. Secara sederhana cara kerjanya dengan menghubungkan Arduino Ethernet Shield dengan board Arduino, kemudian disambungkan ke jaringan internet dengan kabel RJ-45, maka Arduino akan terkoneksi langsung ke internet [6].

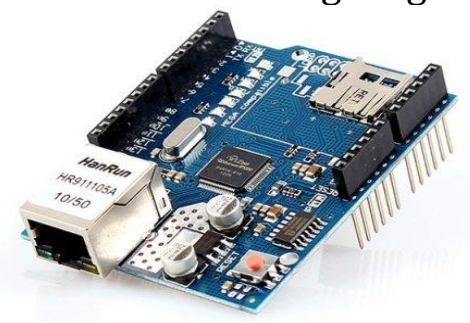

\section{Gambar 1. Ethernet Shield}

\subsection{Sensor ACS712}

Sensor yang digunakan untuk pengukuran arus AC atau DC di dunia industri, komersial, dan sistem komunikasi dimana perangkat ini terdiri dari rangkaian sensor efek-hall yang linier, low-offset, dan presisi sehingga saat arus mengalir maka rangkaian sensor efek-hall mendeteksinya dan mengubahnya menjadi tegangan yang proporsional [10]. 


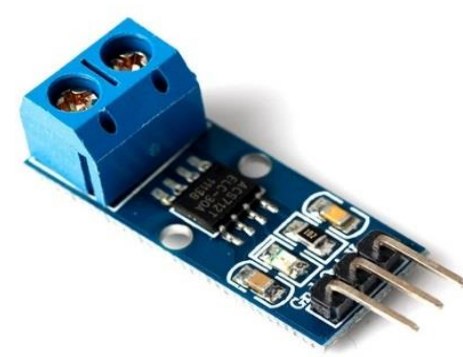

Gambar 2. Sensor ACS712

\subsection{Metode Pengembangan Sistem (Prototype)}

Merupakan tahap-tahapan yang dilakukan oleh analis sistem dan programer dalam membangun sistem informasi yang refresentatif

\subsection{Desain Sistem}

Desain Sistem pada monitoring pengukur tegangan listrik di POLRES Lubuklinggau terdiri dari beberapa desain utama, yaitu:

a. Desain Catu Daya

Pada desain ini digunakan sebagai sumber tenaga listrik yang digunakan oleh perangkat pada arduino.

b. Desain Perangkat Input

Desain ini meliputi desain modul ACS712

c. Desain Perangkat Proses

Desain pada modul perangkat Arduino, dan Ethernet Shield.

d. Desain Perangkat Output

Pada desain ini meliputi desain Web, sebagai tampilan monitoring indikator. Untuk lebih jelasnya, dapat dilihat pada gambar:

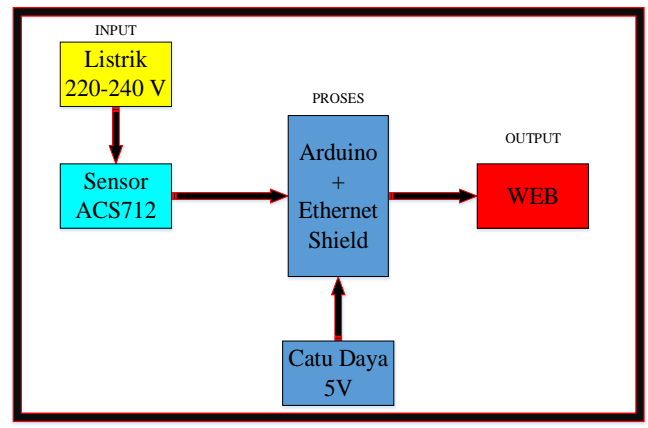

Gambar 3. Diagram Sistem

\section{HASIL DAN PEMBAHASAN}

\subsection{Hasil Perangkat Keras}

a. Rangkaian Pengukur Tegangan Listrik

Perangkat input yang digunakan sensor dht11 yang berfungsi mendeteksi suhu dan kelembaban seperti yang ditunjukkan pada gambar berikut: 


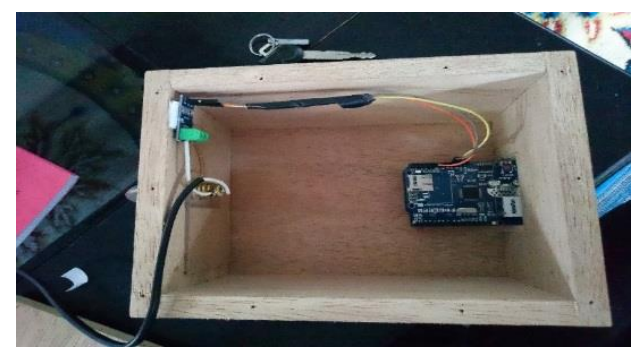

Gambar 4. Rangkaian Arduino dan Sensor ACS712.

b. Hasil Catu Daya

Hasil catu daya Monitoring Tegangan Listrik Melalui Web Berbasis Arduino di Polres Kota Lubuklinggau yaitu perencanaan pada catu daya yang digunakan pada sistem yang digunakan berupa baterai $9 \mathrm{~V}$.

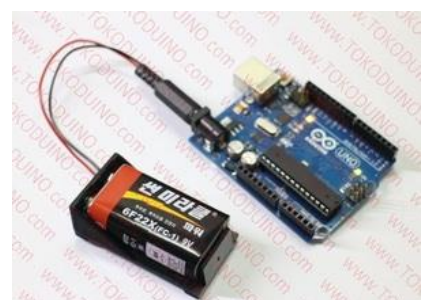

Gambar 5. Hasil Catu Daya

c. Hasil Input ACS712 dan Arduino

Pada hasil input ACS712 dan Arduino terdapat Vcc (kabel merah) pada sensor ACS712 dihubungkan ke pin 5 volt di Arduino uno. Kemudian Gnd (kabel hitam) pada sensor ACS712 dihubungkan ke pin Gnd Arduino uno, sedangkan Output sensor (kabel hijau) pada sensr ACS712 dihubungkan ke pin A0 pada Arduino uno.

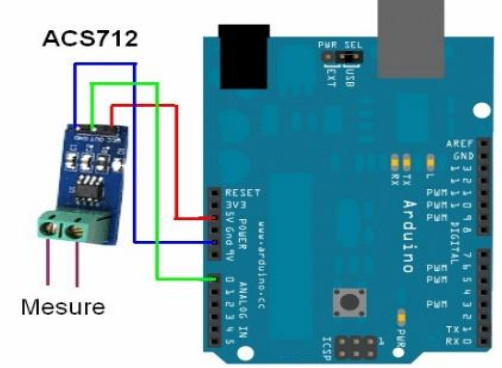

Gambar 6. Hasil Input ACS712

\subsection{Hasil Desain Sistem}

a. Tampilan nilai sensor ACS712

Berikut tampilan nilai sensor ACS712: 


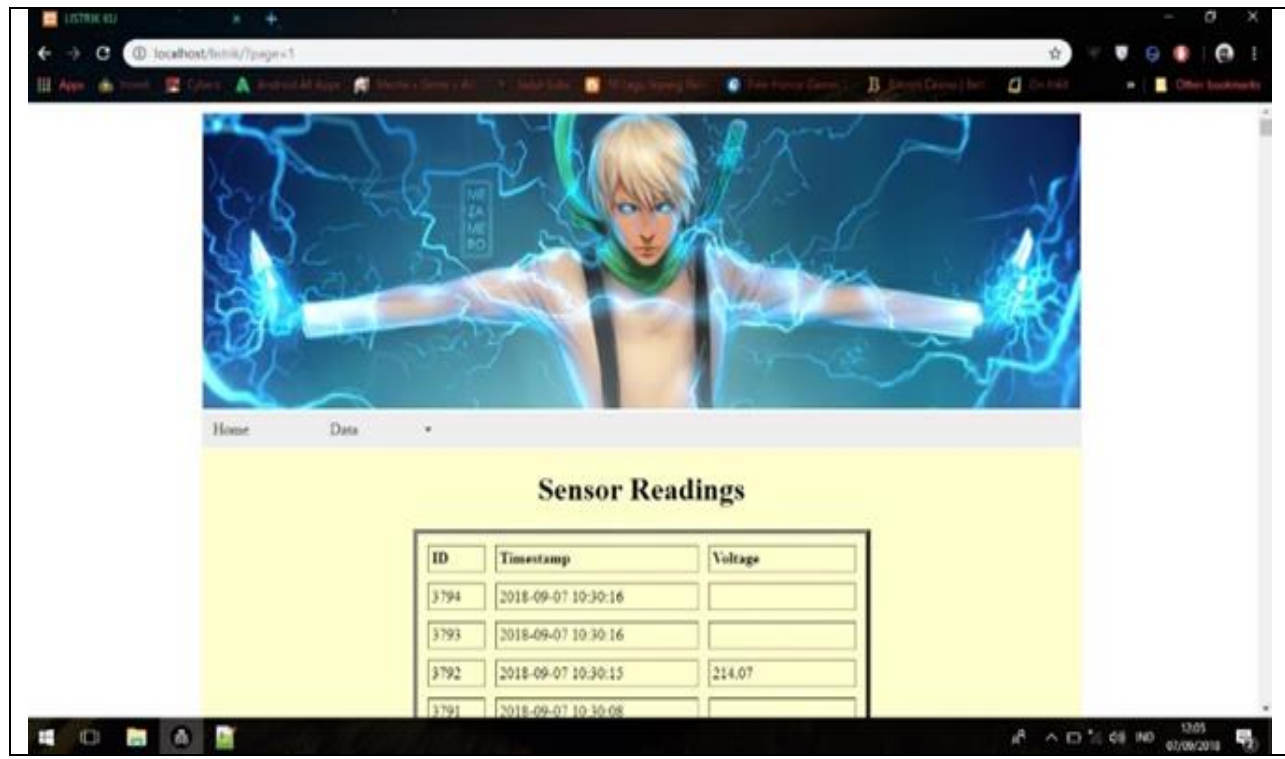

Gambar 7. Tampilan Nilai Sensor

b. Tampilan Data sensor ACS712

Untuk malihat data yang tersimpan di Histori web data sensor maka bisa mengklik pada menu sebelah kanan layar tampilan.

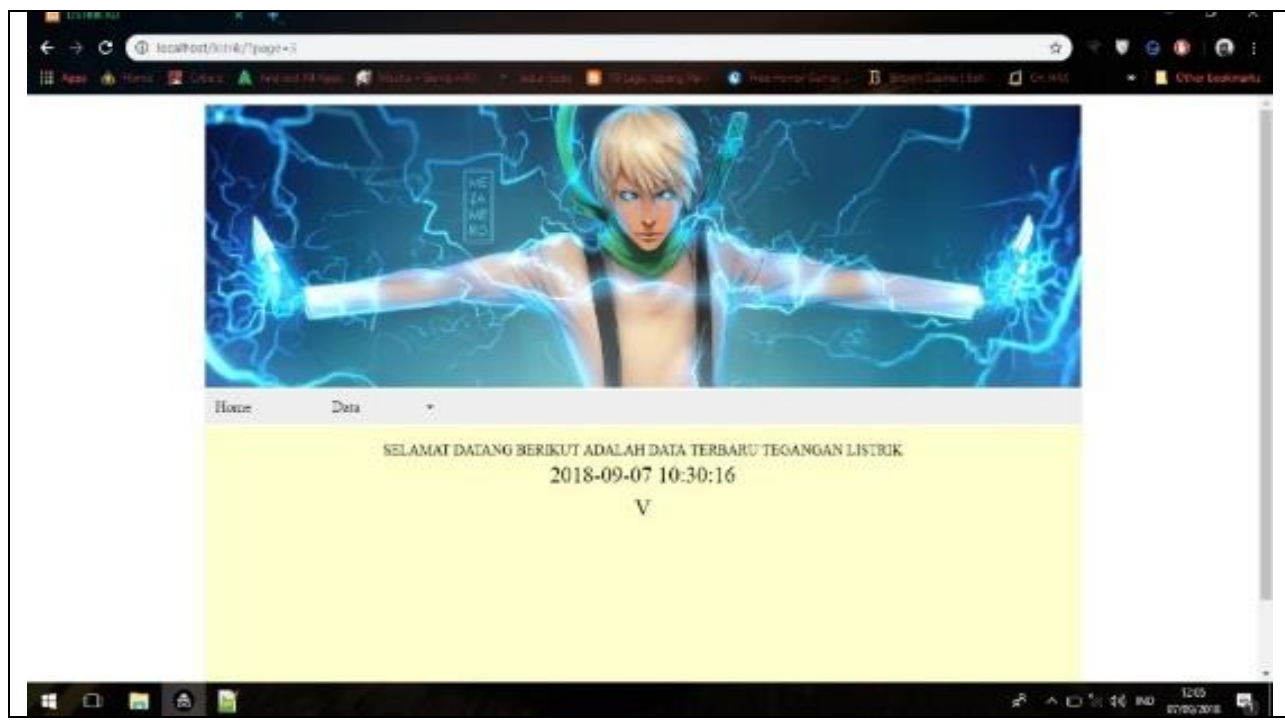

Gambar 8. Tampilan Data sensor

c. Hasil Pengujian Alat

Pengujian meliputi aspek fungsionalitas sistem secara keseluruhan, apakah dapat berfungsi sesuai dengan yang di ingikan atau tidak. Pengujian ini dilakukan agar semua berjalan dengan normal tanpa ada kekurangan. 


\begin{tabular}{|c|c|c|}
\multicolumn{3}{|c}{ Tabel 1. Hasil Pengujian Alat } \\
\hline ID & Time & Voltage (V) \\
\hline 5 & $2018-09-07$ 10:43:34 & 214.92 \\
\hline 4 & $2018-09-0710: 43: 24$ & 218.45 \\
\hline 3 & $2018-09-0710: 43: 14$ & 220.14 \\
\hline 2 & $2018-09-0710: 43: 04$ & 215.84 \\
\hline 1 & $2018-09-07$ 10:42:54 & 223.78 \\
\hline
\end{tabular}

\section{SIMPULAN}

Dari pembahasan dan pengujian pada penelitian maka dari itu dapat disimpulkan dari Monitoring Tegangan Listrik Melalui Web Berbasis Arduino Di POLRES Kota Lubuklinggau (Studi Kasus POLRES Lubuklinggau) yaitu sebagai berikut:

a. Sistem monitoring tegangan listrik menggunakan sensor ACS712 yang bertujuan untuk mengukur tegangan listrik di POLRES kota lubuklinggau Sistem ini dapat mengetahui tegangan listrik yang dipakai.

b. Alat pengukur tegangan listrik ini digunakan untuk memonitoring tegangan listrik yang digunakan di POLRES kota lubuklinggau, nilai dari pembacaan sensor ACS712 nantinya akan tampil di web dan tersimpan di dalam database.

\section{DAFTAR PUSTAKA}

[1] Adi Putra Harahap, Wakhyu Dwiono, Noptin Harpawi, "Rangkaian Perangkat Keras Pengalih Sumber Listrik Berbasis Sms,"Politeknik Caltex Riau, 2012

[2] Irwan Dinata, Wahri Sunanda, "Implementasi Wireless MonitoringEnergi Listrik Berbasis Web Database," Universitas Bangka Belitung, 2015.

[3] Fransiscus, Harianto, Susijanto Tri Rasmana, "Rancang Bangun Alat Pembatas Arus Listrik Dan Monitoring Pemakaian Daya Pada Rumah Sewa Berbasis Mikrokontroler Arduino Uno",Stikom Surabaya, 2016.

[4] Yulizar, Ira Devi Sara, Mahdi Syukri, "Prototipe Pengukuran Pemakaian Energi Listrik Pada Kamar Kos Dalam Satu Hunian Berbasis Arduino Uno R3 Dan Gsm Shield Sim900,"UniversitasSyiah Kuala, 2016.

[5] AfrizalFitriandi,Endah Komalasari, Herri Gusmedi, "Rancang Bangun Alat Monitoring Arus Dan Tegangan Berbasis Mikrokontroler Dengan Sms Gateway," Universitas Lampung, 2016.

[6] Edy Winarno, Ali Zaki, Buku Fisika Dasar, Semarang, 2013.

[7] Betha Sidik, Buku Pemrograman Web Dengan Php 7, Informatika Bandung, 2017.

[8] Firmansyah Saftari, Buku Proyek Robotika Keren Dengan Arduino, Pt Elex Media Komputindo, 2015.

[9] Mada Sanjaya, Buku Membuat Robot Arduino Bersama Profesor Bolabot Menggunakan Interface Python, Gava Media, 2015.

[10] Muhammad Syahwil, Buku Panduan Mudah Simulasi Dan Praktek Mikrokontroler Arduino, Andi Yogyakata, 2013.

[11] Edy Winarno St, M.Eng, Ali Zaki, Buku Membuat Sendiri Jaringan Komputer, Semarang, 2013. 